\title{
Estudos epidemiológicos e seus impactos na saúde da criança: International Study of Asthma and Allergies in Childhood (ISAAC)
}

\section{Epidemiological studies and their impact in children's health: International Study of Asthma and Allergies in Childhood (ISAAC)}

Na última década, os estudos epidemiológicos em doenças alérgicas ganharam grande impulso e nos permitiram conhecer pela primeira vez a real dimensão da asma, rinite e ezcema atópico tanto em crianças e adolescentes, (International Study of Asthma and Allergies in Childhood, ISAAC) ${ }^{1}$ como em adultos (European Community Respiratory Health Survey, ECRHS). Eles foram idealizados em resposta à necessidade de existirem dados confiáveis, obtidos por método reprodutível, e capazes de demonstrar de modo categórico a elevação na prevalência da asma e das doenças alérgicas, muito relatadas no início dos anos 90. Isso foi possível graças à aquisição de instrumentos simples e autoaplicáveis, os questionários escritos (QE) e os vídeo-questionários, que embora tenham sido avaliados quanto às suas características nas populações de origem, é imprescindível que sejam validados ao serem utilizados em outras populações.

A validação de um instrumento indica se o mesmo é realmente capaz de medir aquilo ao que se propôs. Ao realizar a validação de um questionário, deve-se ter conhecimento dos conceitos de sensibilidade (proporção dos indivíduos com a doença que têm um teste positivo para a mesma, isto é, os verdadeiramente doentes) e especificidade (proporção dos indivíduos sem a doença que têm um teste negativo, isto é, os verdadeiramente não-doentes). Outro fator a ser avaliado com os $\mathrm{QE}$, diz respeito à sua reprodutibilidade, testada por meio da sua aplicação duas ou mais vezes ao mesmo indivíduo, com intervalo de tempo definido entre elas. A reprodutibilidade se baseia no fato de que a condição investigada não muda no intervalo de tempo entre as avaliações, em geral, apontado como ideal entre duas e quatro semanas. Todos esses cuidados foram tomados com o QE padrão do ISAAC ao ser empregado em nosso meio. A sua aplicação a adolescentes com asma documentou que a questão "ter sibilos no último ano" revelou ter maiores índices de sensibilidade e especificidade na identificação dos "doentes".2

A primeira fase do ISAAC, concluída em 1996, reuniu pela primeira vez no mundo uma casuística jamais avaliada. Participaram dessa fase 119 centros de 45 países na Europa, Ásia, África, América do Norte, América do Sul e Oceania com um total de 366.106 adolescentes entrevistados (13 e 14 anos) e 74 centros de 34 países, com um total de 208.723 estudantes entrevistados (6 e 7 anos). A análise preliminar desses dados mostrou resultados muito variados. A prevalência de "sibilos no último ano" variou entre 1,6\% e 27,2\% na faixa de 6 a 7 anos e entre 1,9 a $34,1 \%$ na de 13 a 14 anos, e a de asma diagnosticada por médico oscilou entre $1,3 \%$ e $30,8 \%$ (6 a 7 anos) e entre 1,8\% e 30,2\% para os adolescentes. Os valores mais baixos foram documentados na República da Geórgia e Estônia e os mais elevados na Austrália. ${ }^{3}$

No Brasil, participaram oficialmente da primeira fase do ISAAC sete centros (Recife, Salvador, Uberlândia, Itabira, São Paulo-Sul, Curitiba e Porto Alegre) e foram avaliados 13.604 escolares (6 e 7 anos) e 20.554 adolescentes (13 e 14 anos). 4 A prevalência média de asma diagnosticada por médico foi mais elevada entre os meninos de 6 e 7 anos (7,3\% x 4,9\%, respectivamente) e entre as adolescentes $(9,8 \%$ x 10,2\%, respectivamente) quando comparados aos do sexo oposto. ${ }^{4}$ A prevalência de "sibilos nos últimos 12 meses" variou entre $16,1 \%$ (Itabira) e 27,2\% entre os escolares (6 e 7 anos) com índice mais elevado em Recife e Porto Alegre. ${ }^{3}$ Entre os adolescentes, ela variou de 9,6\% (Itabira) a 27,1\% (Salvador) sendo também elevada em Recife (24,7\%). As formas mais graves de asma foram predominantes entre os adolescentes. ${ }^{4,5}$ Tais dados confirmaram ser a prevalência de asma diagnosticada por médico significantemente inferior à de "sibilos nos últimos 12 meses", reforçando a idéia de sub-diagnóstico se aquele critério for utilizado. Outro ponto importante observado foi não ser a gravidade da asma dependente da sua prevalência, uma vez que a maior prevalência de asma grave foi observada em Itabira. ${ }^{4}$ Em comparação a todos os centros participantes da fase I, o Brasil ficou localizado no oitavo lugar entre os com maiores índices. ${ }^{3}$

Finda a fase I do ISAAC pode-se consolidá-lo como protocolo de grande valia no estudo epidemiológico da asma na criança e no adolescente. Os resultados da fase III do ISAAC, recém-terminada e ainda não divulga- 
dos, serão importantes para que possamos saber se, à semelhança de outros países, a prevalência da asma está aumentando ou não. O conhecimento da real dimensão da asma e das doenças alérgicas em nosso meio, certamente permitirá que políticas de saúde mais bem orientadas possam ser instituídas tendo-se como principal meta a redução da sua morbimortalidade.

\section{Dirceu Solé}

Professor Titular e Livre-Docente da Disciplina de Alergia, Imunologia Clínica e Reumatologia do Departamento de Pediatria da Escola Paulista de Medicina da Universidade Federal de São Paulo.

\section{Referencias}

1. Asher MI, Keil U, Anderson HR, Beasley R, Crane J, Martinez F, Mitchell EA, Pearce N, Sibbald B, Steward AW, et al. International study of asthma and allergies in childhood (ISAAC): rationale and methods. Eur Respir J 1995; 8: 483-91.

2. Solé D, Vanna AT, Yamada E, Rizzo MC, Naspitz CK. International study of asthma and allergies in childhood (ISAAC) written questionnaire: validation of the asthma component among Brazilian children. J Invest Allergol Clin Immunol 1998; 8: $376-82$.

3. ISAAC Steering Committee. Worldwide variation in prevalence of symptoms of asthma, allergic rhinoconjunctivitis, and atopic eczema: ISAAC. The International Study of Asthma and Allergies in Childhood (ISAAC) Steering Committee. Lancet 1998; 351 : 1225-32.

4. Solé D, Yamada E, Vana AT, Werneck G, Freitas LS, Sologuren MJ, Brito M, rosario Filho NA, Stein RT, Mallot J. International study of asthma and allergies in childhood (ISAAC). Prevalence of asthma and asthma-related symptoms among Brazilian schoolchildren. J Invest Allergol Clin Immunol 2001; 11: 123-8.

5. Camelo-Nunes IC, Wandalsen GF, Sole D. Asthma in Brazilian school-age children: a public health matter? J Pediatr (Rio J) 2003; 79: 472-3. 